\title{
How COVID-19 Influences Indian Sectoral Stocks
}

\author{
Johnson A. Oliyide ${ }^{1}{ }^{a}$, Abiodun M. Adetokunbo ${ }^{2}$, Ismail O. Fasanya ${ }^{3}$ \\ 1 Department of Economics, Federal University of Agriculture, Abeokuta, Ogun State, Nigeria, 2 Department of Economics, Augustine University, Epe, \\ Lagos, Nigeria, ${ }^{3}$ School of Economics and Finance, University of the Witwatersrand, Johannesburg, South Africa \\ Keywords: indian sectoral stocks, nonparametric causality in quantiles, covid-19 \\ https://doi.org/10.46557/001c.27111
}

\section{Asian Economics Letters}

Vol. 3, Issue 2, 2022

Studies have documented the strong effect of the COVID-19 pandemic on different world economies. In this study, we examine the influence of COVID-19 cases in India on the country's sectoral stock indices. Our results find that COVID-19 has had a negligible influence on the returns of these stocks; however, it causes them to fluctuate significantly. We provide insights for the government and local and international investors.

\section{Introduction}

The objective of this study is to examine how various sectoral stocks in India have responded to the COVID-19 pandemic. The motivation for this study is as follows. First, stock markets respond to news as well as information related to the COVID-19 pandemic (Akhtaruzzaman et al., 2021; Salisu \& Sikiru, 2020). Second, the COVID-19 pandemic has had adverse effects on the global economy, increased uncertainty in stock markets, and reduced stock returns, thereby creating a bottleneck for investment (Padhan \& Prabheesh, 2021). Third, countries, industries, and firms have responded heterogeneously to the COVID-19 pandemic (Bannigidadmath et al., 2021; Song et al., 2021). Fourth, India's financial market is not fully mature and developed (Kumari \& Mahakud, 2015) and is characterized by information inefficiency (Hiremath, 2014). India's stock market is characterized by reforms, changes in market structure and trading practices, and increasing integration with the global economy (Hiremath \& Kattuman, 2017). India is a lower middle income country passing through the second wave of the COVID-19 pandemic, and it currently ranks second in terms of total numbers of COVID-19 cases (Chakraborty et al., 2021; Dravid et al., 2021). All these factors are believed to have important implications for the economy's stock market.

The literature on the effects of the COVID-19 pandemic on the stock market is growing. Padhan \& Prabheesh (2021) emphasize one of the economic effects of COVID-19 and its adverse effect on stock market performance. The COVID-19 pandemic has negatively affected stock market returns (Padhan \& Prabheesh, 2021; Salisu \& Sikiru, 2020; Takyi \& Bentum-Ennin, 2021), increased stock markets contagion (Abuzayed et al., 2021; Akhtaruzzaman et al., 2021), and raised stock market crash risk (Liu et al., 2021). While the majority of these studies examine the COVID-19-stock market nexus across trading regions and advanced stock markets, no study has analyzed the effect of COVID-19 on sectoral stock indices in India, whence we derive our contribution.

The contributions of this study are threefold. First, the study contributes to limited research on the influence of the COVID-19 pandemic on the Indian stock market by examining the influence of COVID-19 on seven Indian sectoral stock indices. Second, unlike Mishra et al. (2020), who use a Markov switching vector autoregression model, we employ the nonlinear causality (causality-in-quantiles) test of Balcilar et al. (2017), which can account for causality at the first moment and higher-order moments. The motivation for this approach hinges on the understanding that high-frequency series distributions have inherent non-normal distributions, such that a linear framework would be deem inappropriate for meaningful inferences (Adekoya et al., 2021).

In the next section, we present the data and methodology. Section III presents the empirical results. Section IV concludes the study.

\section{Data and methodology}

\section{A. Data}

We utilize two sets of data. First, we derive the sectoral stock indices of India from DataStream data. Second, we utilize data on COVID-19 cases in India from the World Health Organization (WHO) data bank as a proxy for COVID-19. The data span from January 31, 2020, to December 31, 2020. For the sake of our analysis, we transform the indices to returns and utilize the growth rate of the number of COVID-19 cases. 


\section{B. Methodology}

As noted in the introduction, we apply the nonparametric causality-in-quantiles approach of Balcilar et al. (2017) for our study. Before proceeding with the nonlinear causality analysis, we utilize the test of Brook et al. (1996, BDS) to examine whether the relation between the number of COVID-19 cases and Indian sectoral stocks is nonlinear. The test shows the inappropriateness of linear Granger causality and reveals evidence of a regime and nonlinearity that can suitably be accounted for by our favored technique (Fasanya et al., 2021).

The approach of Balcilar et al. (2017) is an improved version of the methodological frameworks of Nishiyama et al. (2011) and Jeong et al. (2012). Balcilar et al. are of the opinion that presenting only the causality-in-mean result is not sufficient to demonstrate causality.

There is a need to also disclose causality at higher-order moments. Balcilar et al. (2017), amongst others, base their argument on the fact that causality can vary at different moments. In this vein, the suggested null hypothesis of no causality should be tested through the use of the following equations:

$$
\begin{gathered}
H_{0}=P\left\{F_{y_{t}^{k} \mid W_{t-1}}\left\{Q_{\sigma}\left(y_{t} \mid W_{t-1}\right)\right\}=\sigma\right\}=1, \\
\quad \text { for } k=1,2, \ldots, k \\
H_{1}=P\left\{F_{y_{t}^{k} \mid W_{t-1}}\left\{Q_{\sigma}\left(y_{t} \mid W_{t-1}\right)\right\}=\sigma\right\}<1, \\
\quad \text { for } k=1,2, \ldots, k
\end{gathered}
$$

Overall, we test that $x_{t}$, the number of COVID-19 cases in India, Granger-causes $y_{t}$, India's sectoral stock indices, in the $\sigma$ th quantile up to the $K$ th moment.

\section{A. Preliminary analysis}

\section{Empirical results}

We start with preliminary analyses, whose results are presented in Tables $\underline{1}$ and $\underline{2}$. Apart from the financial sector, which has zero returns on average, Table 1 reveals that all sectors have positive returns, with the technology sector having the highest returns. The average number of COVID-19 cases in India is also high. The standard deviation shows that the series fluctuate significantly. The Jarque-Bera statistics, which corroborate the findings from the skewness and kurtosis statistics, show that not all the series are normally distributed. Lastly, the unit root results show that all the series are stationary in terms of levels.

From the foregoing analysis, we can deduce two things. One, the fluctuations in the series could be a result of the COVID-19 pandemic. Thus, the influence of the COVID-19 pandemic on sectoral stock indices is pertinent to determine. Two, the result from the skewness, kurtosis, and Jarque-Bera statistics suggest the possibility of nonlinearity in the series (Adekoya et al., 2021). We therefore use the BDS test to further test for nonlinearity in the series.
As shown in Table 2, the BDS test largely confirms the presence of nonlinearity in the series. The linear causality test is thus inappropriate for our work, for two main reasons. First, the linear causality test could produce biased results due to undesirable features of the series. Second, our approach to causality can capture causality at different quantiles.

\section{B. Nonparametric causality}

In this section, we present the results of the causal flow from COVID-19 cases in India to the country's individual sectoral stock indices. We use three quantiles for categorization: the first is the bearish market condition (the low quantile, which ranges between 0.1 and 0.3 ), the second is the normal market condition (the middle quantile, which ranges between 0.35 and 0.6 ), and the last is the bullish market condition (the high quantile ranges between 0.65 and 0.9). As shown in Figure 1, COVID-19 cases influence the movements of the India sectoral stock indices more at the variance (higher-order moments) than at the mean (first moment, i.e., returns). Except for the consumer staple sector, whose returns are influenced at the middle quantile, COVID-19 cases in India do not influence the returns of sectoral stock.

Our findings in this study provide many insights. The inability to reject the null hypothesis at the first moment suggests that investors can benefit from these sectors by investing in them. This result is supported by the positive average values of the return series of most of the sectors, even in the face of the COVID-19 pandemic. However, since the volatility of these market series has been justified as being influenced by the number of COVID-19 cases, investors in all sectors should consider the fluctuations in the market before making investment decisions.

Unlike WTI crude oil and the US stock market, which Adekoya et al. (2021) noted to be notably affected by the COVID-19 pandemic, our study supports the claim that the Indian economy is suitable for investment purposes. Thus, the Indian government and financial experts should put in place measures that can boost the confidence of investors in India's financial market.

\section{Conclusion}

This study is informed by the notable influence of the COVID-19 pandemic on different economies. We utilize nonparametric causality in quantiles to examine how COVID-19 cases in India track the workings of the country's sectoral stock indices. Our results reveal that the general influence of COVID-19 on sectoral stock returns in India is negligible. However, the pandemic has caused significantly fluctuations in the stock indices. Future research should focus on how Indian sectoral stocks link to crude oil and performance in different crisis periods. 
Table 1. Descriptive statistics and unit root

\begin{tabular}{|c|c|c|c|c|c|c|c|c|}
\hline & Basic Materials & Consumer Staples & Financials & Health Care & Industrials & Technology & Telecom & India COVID-19 cases \\
\hline Mean & 0.080 & 0.033 & 0.000 & 0.163 & 0.080 & 0.157 & 0.047 & 3214113 \\
\hline Max & 6.484 & 9.064 & 7.427 & 8.588 & 5.004 & 8.547 & 10.339 & 10266674 \\
\hline Min & -14.605 & -10.469 & -17.758 & -8.086 & -14.532 & -9.015 & -11.668 & 5 \\
\hline Std. & 2.048 & 1.666 & 2.542 & 1.701 & 1.838 & 2.061 & 2.570 & 3731795 \\
\hline Skew & -2.166 & -0.152 & -1.906 & -0.332 & -2.689 & -0.496 & -0.134 & 0.714 \\
\hline Kurtosis & 15.847 & 15.431 & 13.866 & 9.305 & 20.431 & 8.061 & 7.086 & 1.861 \\
\hline Jarque-Bera & $1838.116^{* * *}$ & $1546.181^{* * *}$ & $1326.158^{* * *}$ & $401.883^{* * *}$ & $3327.587^{* * *}$ & $265.954^{* * *}$ & $167.694^{* * *}$ & $33.364^{* * *}$ \\
\hline Unit root (ADF) test & $-16.356^{* * *}$ & $-18.725^{* * *}$ & $-15.648^{* * *}$ & $-17.136^{* * *}$ & $-17.873^{* * *}$ & $-18.046^{* * *}$ & $-17.118^{* * *}$ & $-4.006^{* * *}$ \\
\hline
\end{tabular}

Notes: **** denotes the rejection of the null hypothesis at $1 \%$ level of significance. The null hypothesis of the Jaque-Berra test is that the series are normally distributed, while that of the Unit root test is that the series has a unit root. 
Table 2. BDS test

\begin{tabular}{|c|c|c|c|c|c|}
\hline \multicolumn{6}{|c|}{$m$} \\
\hline Variables & 2 & 3 & 4 & 5 & 6 \\
\hline Basic Materials & $\begin{array}{c}0.013 \\
(0.012)^{* *}\end{array}$ & $\begin{array}{c}0.036 \\
(0.000)^{* * *}\end{array}$ & $\begin{array}{c}0.051 \\
(0.000)^{* * *}\end{array}$ & $\begin{array}{c}0.059 \\
(0.000)^{* * *}\end{array}$ & $\begin{array}{c}0.059 \\
(0.000)^{* * *}\end{array}$ \\
\hline Consumer Staples & $\begin{array}{c}0.030 \\
(0.014)^{* *}\end{array}$ & $\begin{array}{c}0.057 \\
(0.000)^{* * *}\end{array}$ & $\begin{array}{c}0.076 \\
(0.000)^{* * *}\end{array}$ & $\begin{array}{c}0.089 \\
(0.000)^{* * *}\end{array}$ & $\begin{array}{c}0.089 \\
(0.000)^{* * *}\end{array}$ \\
\hline Financials & $\begin{array}{c}0.013 \\
(0.011)^{* *}\end{array}$ & $\begin{array}{c}0.046 \\
(0.000)^{* * *}\end{array}$ & $\begin{array}{c}0.071 \\
(0.000)^{* * *}\end{array}$ & $\begin{array}{c}0.084 \\
(0.000)^{* * *}\end{array}$ & $\begin{array}{c}0.089 \\
(0.000)^{* * *}\end{array}$ \\
\hline Health Care & $\begin{array}{c}0.025 \\
(0.000)^{* * *}\end{array}$ & $\begin{array}{c}0.053 \\
(0.000)^{* * *}\end{array}$ & $\begin{array}{c}0.066 \\
(0.000)^{* * *}\end{array}$ & $\begin{array}{c}0.069 \\
(0.000)^{* * *}\end{array}$ & $\begin{array}{c}0.064 \\
(0.000)^{* * *}\end{array}$ \\
\hline Industrials & $\begin{array}{c}0.017 \\
(0.000)^{* * *}\end{array}$ & $\begin{array}{c}0.048 \\
(0.000)^{* * *}\end{array}$ & $\begin{array}{c}0.066 \\
(0.000)^{* * *}\end{array}$ & $\begin{array}{c}0.074 \\
(0.000)^{* * *}\end{array}$ & $\begin{array}{c}0.073 \\
(0.000)^{* * *}\end{array}$ \\
\hline Technology & $\begin{array}{c}0.019 \\
(0.000)^{* * *}\end{array}$ & $\begin{array}{c}0.044 \\
(0.000)^{* * *}\end{array}$ & $\begin{array}{c}0.059 \\
(0.000)^{* * *}\end{array}$ & $\begin{array}{c}0.062 \\
(0.000)^{* * *}\end{array}$ & $\begin{array}{c}0.058 \\
(0.000)^{* * *}\end{array}$ \\
\hline Telecom & $\begin{array}{c}0.016 \\
(0.000)^{* * *}\end{array}$ & $\begin{array}{c}0.040 \\
(0.000)^{* * *}\end{array}$ & $\begin{array}{c}0.051 \\
(0.000)^{* * *}\end{array}$ & $\begin{array}{c}0.054 \\
(0.000)^{* * *}\end{array}$ & $\begin{array}{c}0.053 \\
(0.000)^{* * *}\end{array}$ \\
\hline
\end{tabular}

Notes: Table 2 presents results of the BDS test. $m$ represents the number of embedded dimensions which embed the time series into $m$-dimensional vectors, by taking each $m$ succes sive points in the series. Values in the cells represent the BDS test statistic, while the values in the brackets are the probability values. The symbols $* * * *$ and $* *$ indicate rejection of the null hypothesis of independent and identically distributed (i.i.d) residuals at $1 \%$ and $5 \%$ level of significance, respectively. Put in another way, the symbols indicate the rejection of the null hypothesis of linearity.

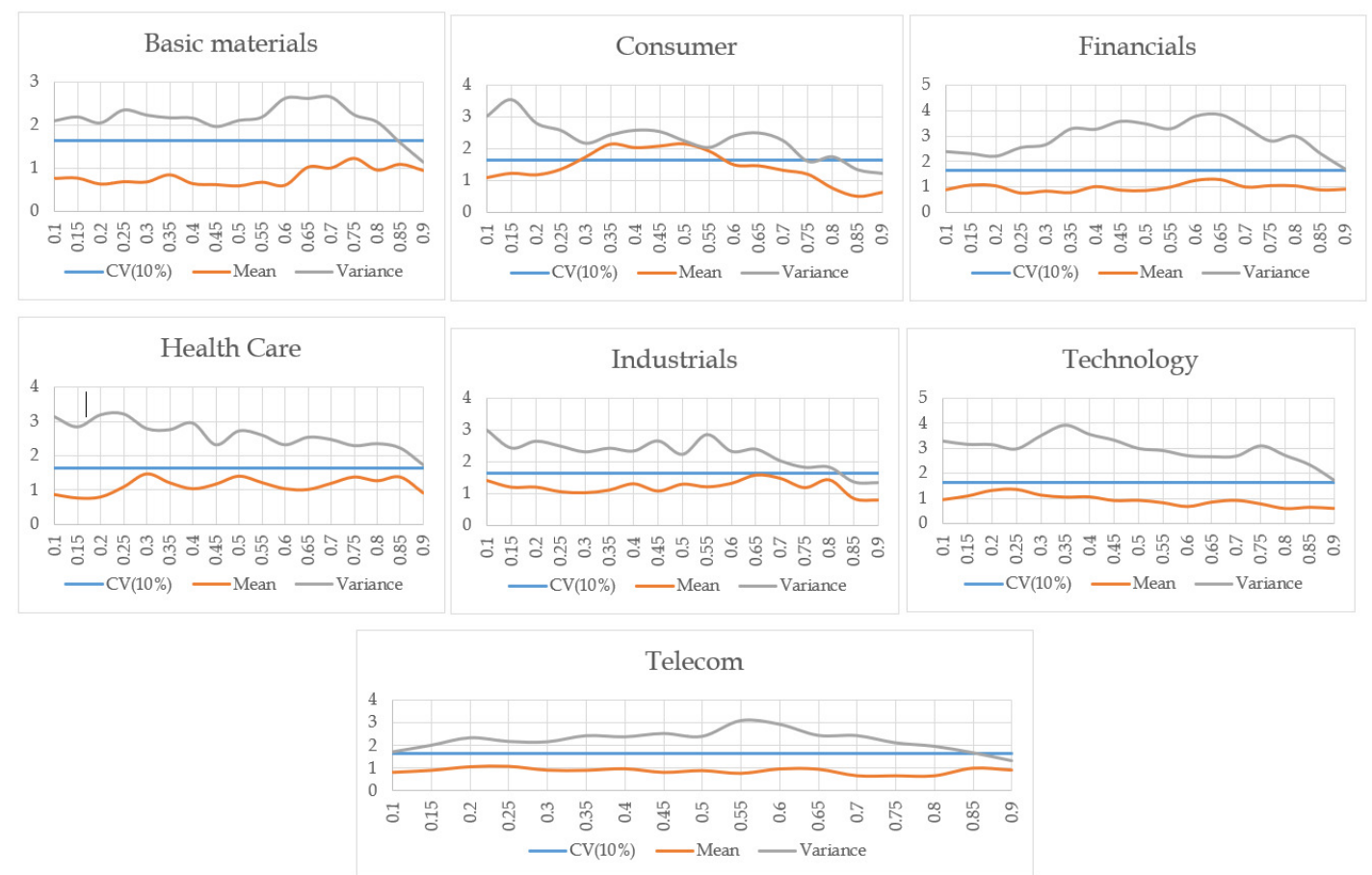

\section{Figure 1. Causality-in-mean and Causality-in-Variance}

Notes: Figure 1 plots the results of the causal influence of COVID-19 cases on sectoral stocks in India at mean and variance. The Y-axis reports the test statistics, while the X-axis reports the quantiles. For the causality in mean, the null is that COVID-19 does not granger cause returns of the stocks, while the null for the causality in variance is that COVID-19 does not granger cause the volatility of the stocks. The decision of rejection or acceptance of the null is hedged on $10 \%$ (1.645). In clear terms, we reject the null when the mean or variance is above the CV line.

Submitted: May 01, 2021 AEST, Accepted: June 22, 2021 AEST

This is an open-access article distributed under the terms of the Creative Commons Attribution 4.0 International License (CCBY-SA-4.0). View this license's legal deed at https://creativecommons.org/licenses/by-sa/4.0 and legal code at https://creativecommons.org/licenses/by-sa/4.0/legalcode for more information. 


\section{References}

Abuzayed, B., Bouri, E., Ali-Fayoumi, N., \& Jalkh, N. (2021). Systemic risk spillover across global and country stock markets during the COVID-19 pandemic. Economic Analysis and Policy, 71, 180-197. https://doi.org/10.1016/i.eap.2021.04.010

Adekoya, O. B., Oliyide, J. A., \& Oduyemi, G. O. (2021). How COVID-19 upturns the hedging potentials of gold against oil and stock markets risks: Nonlinear evidences through threshold regression and markovregime switching models. Resources Policy, 70, 101926. https://doi.org/10.1016/j.resourpol.2020.101 926

Akhtaruzzaman, M., Boubaker, S., \& Sensoy, A. (2021). Financial contagion during COVID-19 crisis. Finance Research Letters, 38. https://doi.org/10.1016/i.frl.202 0.101604

Balcilar, M., Bekiros, S., \& Gupta, R. (2017). The role of news-based uncertainty indices in predicting oil markets: A hybrid nonparametric quantile causality method. Empirical Economics, 53(3), 879-889. http s://doi.org/10.1007/s00181-016-1150-0

Bannigidadmath, D., Narayan, P. K., Phan, H. B., \& Gong, Q. (2021). How stock markets reacted to COVID-19? Evidence from 25 countries. Finance Research Letters, 102161. https://doi.org/10.1016/j.fr $\underline{1.2021 .102161}$

Brook, W., Dechert, D., Scheinkman, J., \& LeBaron, B. (1996). A test for independence based on the correlation dimension. Econometric Reviews, 15(3), 197-235. https://doi.org/10.1080/0747493960880035 $\underline{3}$

Chakraborty, C., Sharma, A. R., Bhattacharya, M., Agoramoorthy, G., \& Lee, S.-S. (2021). The current second wave and COVID-19 vaccination status in India. Brain, Behavior, and Immunity. https://doi.org/1 0.1016/i.bbi.2021.05.018

Dravid, A. N., Mane, D. N., \& Khan, Z. A. (2021). Neurological issues during severe COVID-19 in a tertiary level hospital in Western India. Neuroscience Letters, 749, 135692. https://doi.org/10.1016/i.neule t.2021.135692

Fasanya, I. O., Oliyide, J. A., Adekoya, O. B., \& Agbatogun, T. (2021). How does economic policy uncertainty connect with the dynamic spillovers between precious metals and bitcoin markets. Resources Policy, 72.

Hiremath, G. S. (2014). Indian stock market: An empirical analysis of informational efficiency. SpringerBriefs in Economics.
Hiremath, G. S., \& Kattuman, P. (2017). Foreign portfolio flows and emerging stock market: Is the midnight bell ringing in India? Research in International Business and Finance, 42, 544-558. http s://doi.org/10.1016/j.ribaf.2017.04.016

Jeong, K., Hardle, W. K., \& Song, S. (2012). A consistent nonparametric test for causality in quantile. Econometric Theory, 28(4), 861-887. https://doi.org/1 $\underline{0.1017 / \mathrm{s} 0266466611000685}$

Kumari, J., \& Mahakud, J. (2015). Does investor sentiment predict the asset volatility? Evidence from emerging stock market India. Journal of Behavioral and Experimental Finance, 8(c), 25-39. https://doi.or g/10.1016/j.jbef.2015.10.001

Liu, Z., Huynh, T. L. D., \& Dai, P.-F. (2021). The impact of COVID-19 on the stock market crash risk in China. Research in International Business and Finance, 57, 101419. https://doi.org/10.1016/j.ribaf.2021.101419

Mishra, A. K., Rath, B. N., \& Dash, A. K. (2020). Does the Indian Financial Market Nosedive because of the COVID-19 Outbreak, in Comparison to after Demonetisation and the GST? Emerging Markets Finance and Trade, 56(10), 2162-2180. https://doi.or $\mathrm{g} / 10.1080 / 1540496 x .2020 .1785425$

Nishiyama, Y., Hitomi, K., Kawasaki, Y., \& Jeong, K. (2011). A consistent nonparametric test for nonlinear causality-Specification in time series regression. Journal of Econometrics, 165(1), 112-127. https://doi.o rg/10.1016/j.jeconom.2011.05.010

Padhan, R., \& Prabheesh, K. P. (2021). The economics of COVID-19 pandemic: A survey. Economic Analysis and Policy, 70, 220-237. https://doi.org/10.1016/i.eap.202 1.02.012

Salisu, A. A., \& Sikiru, A. A. (2020). Pandemics and the Asia-pacific Islamic stocks. Asian Economics Letters, 1(1). https://doi.org/10.46557/001c.17413

Song, H. J., Yeon, J., \& Lee, S. (2021). Impact of the COVID-19 Pandemic: Evidence from the U.S. Restaurant Industry. International Journal of Hospitality Management, 92.

Takyi, P. O., \& Bentum-Ennin, I. (2021). The impact of COVID-19 on stock market performance in Africa: A Bayesian structural time series approach. Journal of Economics and Business, 115, 105968. https://doi.org/ 10.1016/j.jeconbus.2020.105968 